\title{
CARACTERÍSTICAS FÍSICAS E QUÍMICAS DE FRUTOS DE MAMOEIRO DO GRUPO 'SOLO' COMERCIALIZADOS EM 4 ESTABELECIMENTOS DE BRASÍLIA-DF ${ }^{1}$
}

\author{
GENI RODRIGUES FAGUNDES 2 , OSVALDO KIYOSHI YAMANISHI ${ }^{3}$
}

\begin{abstract}
RESUMO - As características físicas e químicas do mamão do grupo 'Solo' comercializado em 4 estabelecimentos de Brasília-DF, foram analisadas durante o período de setembro de 1997 a agosto de 1998. Foram coletados, mensalmente, 15 frutos em cada estabelecimento para determinar a sua qualidade. Frutos de plantas hermafroditas representaram $88 \%$ do total. O peso médio variou de $372,2 \mathrm{a} 537,1 \mathrm{~g}$, sendo maior em junho. O comprimento e o diâmetro médio oscilaram entre 12,4 a 14,5cm e 7,6 a 8,7cm, respectivamente. O grau de maturação dos frutos coletados, na sua maioria, não estava no ponto de consumo. A firmeza da polpa dos frutos oscilou de 0,56 a 1,04 $\mathrm{kg} / \mathrm{cm}^{2}$, estando abaixo da firmeza adequada para comercialização. O teor médio de SST variou de $9,9^{\circ}$ a $12,5^{\circ}$ Brix, sendo mais alto em agosto. $\mathrm{O}$ pH oscilou entre 5,20 e 5,71 e foi mais alto em agosto e setembro. A acidez titulável, expressa em ácido cítrico, variou de 0,04 a $0,16 \%$, e a relação SST-AT entre 74,7 e $275,7$.
\end{abstract}

Termos para indexação: Mamão, qualidade, comercialização.

\section{PHYSICAL AND CHEMICAL CHARACTERISTICS OF FRUITS OF PAPAYA TREE FROM 'SOLO' GROUP COMMERCIALIZED IN 4 ESTABLISHMENTS IN BRASILIA-DF}

\begin{abstract}
The physical and chemical characteristics of papaya from 'Solo' group commercialized in 4 establishments located in Brasilia - DF, were analyzed from September 1997 to August 1998. From each establishment 15 fruits were collected monthly to determine fruit quality. Fruits originated from hermaphrodite plants accounted for $88 \%$ of the total. The average fruit weight varied from 372.2 to 537.1 being higher in June. The average size and diameter oscillated from 12.4 to $14.5 \mathrm{~cm}$ and 7.6 to $8.7 \mathrm{~cm}$, respectively. The maturation degree of most collected papaya was not in the consumption stage. The firmness of the fruit pulp ranged from 0.56 to 1.04 $\mathrm{kg} / \mathrm{cm}^{2}$ being below the suitable firmness for commercialization. The average ${ }^{\circ}$ Brix varied from 9.9 to 12.5 being higher in August. The $\mathrm{pH}$ value oscillated from 5.20 to 5.71 being higher in August and September. The titratable acidity (TA), expressed as citric acid, varied from 0.04 to $0.16 \%$ and ${ }^{\circ}$ Brix - TA ratio from 74.7 and 275.7 .
\end{abstract}

Index terms: Papaya, quality, commercialization.

\section{INTRODUÇÃO}

O Brasil é o principal produtor de mamão, participando com $36,9 \%$ do total produzido no mundo (FAO, 1998). No entanto, o mercado interno consome a maior parte da produção total, sendo uma pequena parcela destinada à exportação. A produção brasileira de mamão concentra-se atualmente na região do extremo Sul da Bahia e na região Norte do Espírito Santo, consideradas as principais regiões produtoras do País.

O mamão comercializado no Distrito Federal é quase todo (90\%) fornecido por produtores do Estado da Bahia, havendo uma boa demanda no mercado local.

O mamão é um fruto nutritivo, que apresenta boas qualidades organolépticas. No entanto, para que suas qualidades sejam mantidas é necessário, além de condições adequadas de cultivo, que seja colhido na época e estádio de maturação adequado, e manuseado corretamente após a colheita. A qualidade do fruto depende do estádio de maturação, o qual influencia muito na sua vida útil pós-colheita. Colheitas realizadas antes dos frutos atingirem completa maturação fisiológica prejudicam o seu processo de amadurecimento, afetando a sua qualidade. Por outro lado, a colheita de frutos totalmente maduros reduz sua vida útil, dificulta o seu manuseio e transporte, devido a sua baixa resistência física, causando perdas quantitativas e qualitativas (Chitarra \& Chitarra, 1990). Sendo assim, é importante a determinação do ponto ideal de colheita, seja através de métodos diretos ou seja, para colher frutos de boa qualidade e evitar perdas.

Para estudo das qualidades do fruto, podem ser adotados vários parâmetros, sejam eles físicos como peso, comprimento, diâmetro, forma, cor e firmeza, sejam químicos, como sólidos solúveis totais, $\mathrm{pH}$, acidez titulável e outros. Estas características geralmente são influenciadas pelos seguintes fatores: condições edafoclimáticas, cultivar, época e local de colheita, tratos culturais e manuseio na colheita e pós-colheita, e variam em função do destino do fruto e das exigências do mercado consumidor.

1 (Trabalho 237/2000). Recebido: 27/10/2000. Aceito para publicação: 01/11/2001. Parte da tese do primeiro autor apresentada à Universidade de Brasília, para a obtenção do grau de "Magister Scientiae".

2 Eng. Agr. M.Sc., Faculdade de Agronomia e Medicina Veterinária da Universidade de Brasília. Bolsista DTI do CNPq. E-mail: genifagundes@bol.com.br

3 Eng. Agr. PhD, Professor Adjunto II da Faculdade de Agronomia e Medicina Veterinária da Universidade de Brasília. Bolsista de Pesquisa 2C do CNPq. Campus Universitário Darcy Ribeiro, Caixa Postal 04508, CEP 70.910-970, Brasília, DF. E-mail: kiyoshi@unb.br 
No mamão, a cor da casca é considerada um índice de maturidade bastante confiável, sendo utilizada, para determinar o ponto de colheita do fruto. Souza (1998) verificou que frutos de mamão colhidos no estádio de "duas pintas amarelas" apresentaram melhor associação entre qualidade e manejo póscolheita. A coloração da casca e da polpa do mamão são aspectos que determinam a sua aceitação pelo consumidor, pois este tem preferência por frutos de casca amarela ou alaranjado brilhantes e polpa alaranjada-escura (Fioravanço et al. 1992).

A firmeza do fruto é um atributo de qualidade que pode indicar o seu estádio de maturação ou ponto de colheita, e que influencia na sua comercialização. Assim, frutos com baixa firmeza apresentam menor resistência ao transporte, armazenamento e ao manuseio.

O teor de sólidos solúveis totais (SST) e a acidez titulável (AT) são parâmetros que também podem indicar o ponto de colheita do fruto, pois existe uma relação entre eles e o estádio de maturação do fruto. Segundo Medina (1989) os padrões havaianos requerem para comercialização uma porcentagem mínima de sólidos solúveis de $11,5 \%$ para mamões do grupo 'Solo'. Já Ruggiero (1980) estabeleceu uma porcentagem mínima de sólidos solúveis de $14 \%$, variando de $16 \%$ a $17 \%$ durante os meses de verão e de $13 \%$ a $14 \%$ durante o inverno. De acordo com Hinojosa \& Montgomery (1988), a acidez total da polpa de mamão varia entre $0,12 \%$ e $0,15 \%$ e, devido a essa característica, ele tem sido recomendado como tratamento dietético para pessoas que sofrem de problemas gastrointestinais, como gastrite e úlcera.

O trabalho teve como objetivo analisar as características físicas e químicas dos frutos de mamão do grupo 'Solo', comercializados em 4 estabelecimentos do Plano Piloto, BrasíliaDF, no período de setembro de 1997 a agosto de 1998.

\section{MATERIAL E MÉTODOS}

O trabalho foi realizado em Brasília-DF, no período de setembro de 1997 a agosto de 1998, sendo baseado na coleta mensal de frutos de mamão do grupo 'Solo', em 4 estabelecimentos do Plano Piloto, Brasília-DF (CEASA/DF, Supermercado Pão de Açúcar, Supermercado Planaltão e Varejão Oba). Em cada local foram coletados, aleatoriamente, uma amostra de 15 frutos mais representativos do lote, compondo uma amostra de 60 frutos. As análises foram realizadas no Laboratório de Análise de Alimentos da Universidade de Brasília.

As características analisadas foram: peso, comprimento, diâmetro, cor da casca, firmeza da polpa, sólidos solúveis totais, pH, acidez titulável e determinada a relação SST/AT.

A cor da casca do mamão foi determinada mediante observação visual de acordo com uma carta de cores. A firmeza da polpa foi obtida por penetrômetro, sendo expressa em $\mathrm{kg} / \mathrm{cm}^{2}$. Foi observado o formato de cada fruto inteiro e dividido, associando-o ao tipo de flor que originou (hermafrodita ou feminina). As análises químicas ( $\mathrm{pH}, \mathrm{SST}$ e AT) foram determinadas segundo metodologias de Adolfo Lutz (1976), sendo cada amostra composta por diferentes porções do fruto. A relação SST/AT foi obtida através da divisão dos resultados dos teores de sólidos solúveis totais ( ${ }^{0}$ Brix) e da acidez titulável (\% ácido cítrico).
Aplicou-se o teste de Tukey ao nível de 5\% de significância para comparação das médias de cada mês.

\section{RESULTADOS E DISCUSSÃO}

Verificou-se que o peso médio dos frutos oscilou entre 372,2 e 537,1g durante o período analisado (Tabela 1), sendo que estes valores, com exceção do mês de novembro $(372,2 \mathrm{~g})$, encontram-se dentro dos intervalos obtidos para esta cultivar por Fioravanço et al. (1992), Carvalho et al. (1994) e Souza (1998), que foram de 391,3 a 585,9g, 404,8 a 584,5g e 476,9 e 585,9g, respectivamente. No entanto, foram superiores ao peso médio (360g) obtido por Bleinroth \& Sigrist (1989).

A variação nas características físicas dos frutos está relacionada a fatores como: condições climáticas, tratos culturais, cultivar, época de plantio, colheita e outros. Fioravanço et al. (1992), analisando frutos de mamoeiro do grupo 'Solo' comercializados em Porto Alegre-RS, encontraram maior peso médio nos meses de outubro e novembro, enquanto no presente trabalho, o mês de novembro foi o que apresentou frutos com menor peso médio $(372,2 \mathrm{~g})$, diferindo dos demais meses, com exceção do mês de janeiro.

O tamanho "in natura" do fruto depende das exigências do mercado consumidor. Souza (1998) afirma que para consumo ao natural de mamão do grupo 'Solo' no mercado interno, a preferência é por frutos com peso na faixa de 460 a $690 \mathrm{~g}$, classificados como tipos 9 e 13. Os frutos analisados neste trabalho podem ser classificados como sendo dos tipos: 11 (500 a 549g); 12 (460 a 499g), 13 (420 a 459g), 14 (390 a 419g) e 15 (370 a 389g), segundo classificação citada por Marin et al. (1995) para frutos destinados à comercialização no mercado interno.

O comprimento dos frutos oscilou entre 12,4 a $14,5 \mathrm{~cm}$ e $\mathrm{o}$ diâmetro entre 7,6 e 8,7cm, sendo maior em janeiro e em outubro, respectivamente. Estes valores se aproximaram daqueles encontrados por Fioravanço et al. (1992) em frutos de mamão 'Solo', que variaram de 12,57 a $14,78 \mathrm{~cm}$, para o comprimento, e de 7,86 a $9,21 \mathrm{~cm}$ para diâmetro. Silva (1995) estudando a cultivar 'Sunrise Solo' obteve comprimento médio de aproximadamente $15 \mathrm{~cm}$ e diâmetro de $9 \mathrm{~cm}$. Outros autores também trabalharam com mamões do grupo 'Solo' e obtiveram resultados semelhantes, como Carvalho et al. (1992) que encontraram comprimento e diâmetro médio variando de 13,28 a $14,78 \mathrm{~cm}$ e 7,86 a 9,21 cm; e Souza (1998), 14,52 a 15,48cm e 8,57 a 9,12cm.

A cor da casca dos frutos analisados apresentou valores médios de 2,75 a 4,68 , sendo que grande parte $(66,6 \%)$, estavam no estádio 3, ou seja amarelo com traços verdes, estando próximos do ponto de consumo. O oposto foi verificado por Fioravanço et al. (1992), que observou que 53,5\% dos frutos de mamão 'Solo' analisados apresentaram coloração da casca laranja, $28,65 \%$ coloração amarela e 17,84\% coloração verde.

A cor do fruto é um fator que influencia muito na sua aceitação, pois conforme afirmou Fioravanço et al. (1994) o consumidor tem maior preferência por frutos com casca lisa e de coloração amarela-viva ou alaranjada brilhante em relação aos frutos de casca clara e esverdeada. O consumidor geralmente relaciona a coloração dos frutos com o aumento da doçura e com outros atributos desejáveis e por isso, na hora de comprar, prefere os frutos mais coloridos. No entanto, não é lucrativo para o 
comerciante colocar à venda frutos completamente maduros, pois estes são menos resistentes ao manuseio e apresentam pequena vida de prateleira. Seria interessante então, que o estabelecimento colocasse à venda, frutos em diferentes estádios de maturação, de maneira a atender às preferências dos consumidores.

A firmeza da polpa do mamão variou de 0,56 a $1,04 \mathrm{~kg} / \mathrm{cm}^{2}$ e foi maior em março, diferindo significativamente dos meses de novembro, junho e agosto. Estes valores foram inferiores àqueles verificados por Fioravanço et al (1992), que oscilaram entre 1,34 e $2,87 \mathrm{~kg} / \mathrm{cm}^{2}$. Os baixos valores de firmeza encontrados na polpa dos frutos analisados podem estar relacionados a fatores como o grau de maturação do fruto, a cultivar, tratos culturais, transporte e ao manuseio do fruto na colheita e pós-colheita. Vieira et al. (1998) observaram que o amolecimento ou redução na firmeza da polpa do mamão é mais rápido quando é retardada a colheita. Souza (1998) encontrou valores de firmeza próximos de $1 \mathrm{~kg} / \mathrm{cm}^{2}$ em frutos colhidos no estádio 3, aos 6 dias póscolheita, e segundo ele, este grau de firmeza dificulta o manuseio do fruto no comércio.

Tendo em vista os baixos valores de firmeza verificados nos frutos analisados, recomenda-se que os diversos segmentos envolvidos na comercialização dos frutos (produtores, atacadistas, varejistas, consumidores e outros) adotem formas de manuseio mais adequadas e cuidadosas em todas fases da produção, transporte e comercialização, para evitar danos que reduzem a sua firmeza e consequentemente sua vida útil.

Observou-se que $88 \%$ dos frutos analisados durante todo o período eram originados de flores hermafroditas e apenas $12 \%$ de flores femininas. Fioravanço et al. (1992) estudando frutos de mamão 'Solo' obtiveram uma menor porcentagem, sendo 77,62\% do tipo hermafrodita e $23,38 \%$ do tipo feminino.

Manica (1996) comenta que os grandes mercados consumidores preferem frutos alongados e cilíndricos, provenientes de flores hermafroditas, que são de menor tamanho, com menor cavidade interna, sendo mais resistentes ao transporte e manuseio. Portanto, é importante a obtenção de frutos de mamão originados de flores hermafroditas, para produção de frutos pequenos, de forma ovalada, que atenda a necessidade dos consumidores e reduza os custos de transporte, embalagem e armazenamento.
O teor de sólidos solúveis totais (SST) dos frutos variou de 9,9 a 12,5 ${ }^{\circ}$ Brix (Tabela 2), sendo inferiores aos valores médios $13,3^{\circ}$ Brix e $12,0^{\circ}$ Brix, obtidos por Viegas (1992) para as cultivares 'Sunrise-Solo' e grupo 'Formosa', respectivamente. Fioravanço et al. (1992) analisaram frutos do grupo 'Solo' e encontraram valores de SST oscilando entre 8,68 e 11,66 ${ }^{\circ}$ Brix.

Os frutos coletados em agosto apresentaram maior SST, diferindo dos meses de setembro, dezembro e março. Sabe-se que durante a fase de maturação dos frutos ocorre um aumento no teor de açúcares, que variam com o tipo de mamão, cultivar, condições climáticas, fertilidade do solo, época de produção, estágio de desenvolvimento e maturação.

Verificou-se que os frutos comercializados em dezembro $\left(9,94^{\circ}\right.$ Brix $)$ e janeiro $\left(10,79^{\circ}\right.$ Brix $)$ apresentaram teores de SST abaixo do recomendado para colheita de frutos do grupo 'Solo', que é de $11,5 \%$ de sólidos solúveis totais. Como os frutos comercializados em Brasília-DF, são em grande parte importados da Bahia, onde geralmente são registradas temperaturas elevadas nestes meses, provavelmente estes frutos devem ter sido colhidos mais verdes para resistirem mais ao transporte, apresentando assim menor teor de SST depois de maduros. Portanto é importante fazer a determinação do ponto ideal de colheita, levando em consideração os vários fatores que influenciam suas características químicas e físicas.

$\mathrm{O} \mathrm{pH}$ apresentou pequena variação entre os meses, oscilando entre 5,20 e 5,71,estando estes valores próximos aos obtidos por Fioravanço et al. (1992) e por Souza (1998), variáveis de 5,28 a 5,71 e de 5,43 a 5,86, respectivamente. De acordo com Chan Júnior et al. (1971) o mamão 'Solo' apresenta um pH entre 4,5 e 6,0, baseado nisto pode-se dizer que os frutos comercializados no Plano Piloto de Brasília-DF, no período de setembro de 1997 a agosto de 1998 apresentaram pH dentro do intervalo considerado para consumo ao natural.

A acidez titulável dos frutos apresentou valores entre 0,04 e $0,16 \%$ de ácido cítrico, sendo semelhantes àqueles obtidos por Souza (1998), que foi de $0,043 \%$ de ácido cítrico e por Fioravanço et al. (1992), que variaram de 0,04 a $0,05 \%$ de ácido cítrico.

A relação SST/AT oscilou entre 74,7 e 275,7, e foi superior em junho, que diferiu estatisticamente de todos os meses, estando

TABELA 1 - Peso do fruto, comprimento, diâmetro, cor e firmeza do mamão do grupo 'Solo' comercializado em 4 estabelecimentos do Plano Piloto, Brasília-DF, no período de setembro de 1997 a agosto de 1998.

\begin{tabular}{llllll}
\hline \multicolumn{1}{c}{ Meses } & $\begin{array}{c}\text { Pfruto } \\
(\mathbf{g})\end{array}$ & $\begin{array}{c}\text { Comprimento } \\
(\mathbf{c m})\end{array}$ & $\begin{array}{c}\text { Diâmetro } \\
(\mathbf{c m})\end{array}$ & Cor & $\begin{array}{c}\text { Firmeza } \\
\left(\mathbf{k g} / \mathbf{c m}^{2}\right)\end{array}$ \\
\hline Set./97 & $474,7 \mathbf{a b c}$ & $13,5 \mathbf{b c d e}$ & $8,52 \mathbf{a b}$ & $3,42 \mathbf{b c d}$ & $1,03 \mathbf{a}$ \\
Out./97 & $536,9 \mathbf{a}$ & $14,2 \mathbf{a b}$ & $8,72 \mathbf{a}$ & $3,88 \mathbf{b}$ & $0,79 \mathbf{a b c}$ \\
Nov./97 & $372,2 \mathbf{d}$ & $12,4 \mathbf{f}$ & $7,66 \mathbf{e}$ & $3,56 \mathbf{b c}$ & $0,56 \mathbf{c}$ \\
Dez/97 & $481,1 \mathbf{a b c}$ & $13,6 \mathbf{b c d e}$ & $8,30 \mathbf{a b c}$ & $2,90 \mathbf{d e}$ & $0,90 \mathbf{a b}$ \\
Jan./98 & $436,0 \mathbf{c d}$ & $14,5 \mathbf{a}$ & $7,62 \mathbf{e}$ & $3,71 \mathbf{b c}$ & $0,83 \mathbf{a b c}$ \\
Fev./98 & $524,0 \mathbf{a b}$ & $14,3 \mathbf{a}$ & $8,26 \mathbf{a b c d}$ & $3,55 \mathbf{b c}$ & $0,86 \mathbf{a b c}$ \\
Mar/98 & $457,8 \mathbf{b c}$ & $13,3 \mathbf{c d e}$ & $8,10 \mathbf{b c d e}$ & $2,80 \mathbf{d e}$ & $1,04 \mathbf{a}$ \\
Abr/98 & $487,2 \mathbf{b c}$ & $13,6 \mathbf{b c d e}$ & $7,89 \mathbf{c d e}$ & $3,25 \mathbf{d e}$ & $1,01 \mathbf{a}$ \\
Maio/98 & $529,0 \mathbf{a}$ & $14,1 \mathbf{a b c d}$ & $8,36 \mathbf{a b c}$ & $3,89 \mathbf{b}$ & $0,74 \mathbf{a b c}$ \\
\hline Jun./98 & $537,1 \mathbf{a}$ & $14,1 \mathbf{a b c}$ & $8,16 \mathbf{b c d}$ & $2,75 \mathbf{e}$ & $0,62 \mathbf{b c}$ \\
\hline Jul./98 & $448,5 \mathbf{c}$ & $13,2 \mathbf{d e f}$ & $7,79 \mathbf{e d}$ & $3,88 \mathbf{b}$ & $0,86 \mathbf{a b c}$ \\
Ago./98 & $477,4 \mathbf{a b c}$ & $13,1 \mathbf{e f}$ & $8,00 \mathbf{c d e}$ & $4,68 \mathbf{a}$ & $0,62 \mathbf{b c}$ \\
\hline
\end{tabular}

* Médias seguidas de mesma letra não diferem entre si pelo teste de Tukey ao nível de 5\% de significância. 
TABELA 2 - Sólidos solúveis totais, pH, acidez titulável e relação SST/AT do mamão do grupo 'Solo' comercializado em 4 estabelecimentos do Plano Piloto, Brasília-DF, no período de setembro de 1997 a agosto de 1998.

\begin{tabular}{|c|c|c|c|c|}
\hline M eses & $\begin{array}{c}\text { S S T } \\
\left({ }^{\circ} \text { B rix }\right) \\
\end{array}$ & p H & $\begin{array}{c}\text { A.T. } \\
(\% \text { ác.cítrico) }\end{array}$ & $\frac{\text { S S T }}{\text { A T }}$ \\
\hline S e t/97 & $11,7 \mathbf{b}$ & 5,71 a & $0,07 \mathbf{d e}$ & $107,8 \mathbf{f}$ \\
\hline O u t $/ 97$ & 12,0 a b & 5,44 b c d & 0,09 cd & $151,8 \mathrm{e}$ \\
\hline D e z/97 & $9,9 \mathrm{c}$ & $5,50 \mathrm{~b}$ & 0,09 cd & $111,7 \mathbf{f}$ \\
\hline $\mathrm{J}$ a n $/ 98$ & 10,8 c & $5,40 \quad$ b c & $0,12 \mathbf{b}$ & $102,4 \mathbf{f}$ \\
\hline Fev/98 & 12,2 a b & $5,36 \mathbf{e}$ & $0,13 \mathbf{b}$ & $108,0 \mathbf{f}$ \\
\hline M aio/98 & 11,8 a b & $5,20 \mathrm{~g}$ & $0,16 \mathbf{a}$ & 74,7 \\
\hline J u n /98 & $11,9 \mathbf{a} \mathbf{b}$ & 5,42 cd e & $0,04 \mathbf{e}$ & $275,70 \mathrm{a}$ \\
\hline $\mathrm{J}$ u l/9 8 & 11,8 a b & 5,42 cd e & $0,05 \mathrm{e}$ & 238,48 b c \\
\hline A go/98 & 12,5 a & $5,70 \mathbf{a}$ & $0,07 \mathbf{d} \mathbf{e}$ & 180,82 d e \\
\hline
\end{tabular}

*Médias seguidas de mesma letra na coluna não diferem significativamente entre si, pelo teste de Tukey ao nível de $5 \%$ de confiança.

próximo ao valor obtido por Viegas (1992), para a cultivar SunriseSolo, que foi de 267,0 .

\section{CONCLUSÕES}

- O peso médio dos frutos do mamão do grupo 'Solo' analisados variou de 372,2 a 537,1g sendo maior em junho, estando dentro da faixa de peso considerada de maior preferência para consumo interno. O comprimento e o diâmetro médio oscilaram entre 12,4 a $14,5 \mathrm{~cm}$ e 7,6 e $8,7 \mathrm{~cm}$, respectivamente. Grande parte dos mamões coletados não estavam no ponto de consumo, apresentando-se nos estádios 2, 3 e 4 . A firmeza da polpa dos frutos apresentou valores um tanto baixos $\left(0,56-1,04 \mathrm{~kg} / \mathrm{cm}^{2}\right)$.

- $88 \%$ dos mamões coletados originaram-se de flores hermafroditas.

- O teor médio de SST variou de 9,9 a $12,5^{\circ} \mathrm{Brix}$, sendo maior em agosto. $\mathrm{O} \mathrm{pH}$ oscilou entre 5,20 e 5,71 e foi maior em agosto e setembro. A acidez titulável apresentou valores entre 0,04 e 0,16\% de ácido cítrico e a relação SST/AT entre 74,7 e 275,7.

\section{REFERÊNCIAS BIBLIOGRÁFICAS}

BLEINROTH, E.W.; SIGRIST, J.M.M. Matéria-prima. In: ITAL. Mamão: cultura, matéria-prima, processamento e aspectos econômicos. 2. ed., Campinas: ITAL, cap.2, p.179-254. 1989 (Série frutas tropicais, 7).

CARVALHO, R.I.N.; FIORAVANÇO, J.C.; PAIVA, M.C.; MANICA, I. Características físicas e químicas do mamão "Papaya" comercializado em Porto Alegre. Revista Brasileira de Fruticultura, Cruz das Almas, v.14, n.1, p.143-147, 1992.

CARVALHO, J.G. de; OLIVEIRA JR., J.P. de; PAULA, M.B. de; BOTREL, N. Influência dos nutrientes na qualidade de frutos. Informe Agropecuário, Belo Horizonte, v.17, n.180, p.52-55, 1994.

CHAN JR., H.T. et al. Nonvolatile acids of papaya. J. Agr. Food Chem.,n.19, p.263-265. 1971.

CHITARRA, M.I.F.; CHITARRA, A.D. Pós-colheita de frutos e hortaliças: Fisiologia e Manuseio. Lavras: ESAL/FAEPE, 1990.
$320 \mathrm{p}$

FAO. Production Yearbook, Roma, 1998.

FIORAVANÇO, J.C.; PAIVA, M.C.; CARVALHO, R.I.N. de.; MANICA, I. Qualidade do mamão Papaya comercializado em Porto Alegre de outubro/91 a junho/92. 1992 (em fase de publicação).

FIORAVANÇO, J.C.; PAIVA, M.C.; CARVALHO, R.I.N. de.; MANICA, I. Características do mamão Formosa comercializado em Porto Alegre de outubro/91 a junho/92. Ciência Rural, Santa Maria, v.24, n.3, p.519-522, 1994.

HINOJOSA, R.L.; MONTGOMERY, M.W. Industrialização do mamão: aspectos químicos e tecnológicos da produção de purê asséptico. In: Simpósio sobre a cultura do mamoeiro, 2., Jaboticabal, 1988. Anais... Jaboticabal, FCAV/UNESP, p.89-110. 1988.

INSTITUTO ADOLFO LUTZ. Normas analíticas do Instituto Adolfo Lutz. São Paulo, 1976. v.1.371p.

MANICA, I. Cultivares e melhoramento do mamoeiro. In: MENDES, L.G.; DANTAS, J.L.L.; MORALES, C.F.G. Mamão no Brasil. Cruz das Almas: EMBRAPA-CNPMF, 1996. 179p.

MARIN, S. L. D.; GOMES, J. A.; SALGADO, J. S.; MARTINS, D. S.; FULLIN, E. A. Recomendações para a cultura do mamoeiro dos grupos Solo e Formosa no Estado do Espírito Santo. 4 ed., rev. ampl. Vitória: EMCAPA, 1995. 57 p.

MEDINA, J.C. Cultura. In: MEDINA, J.C.; BLEINROTH, E.W.; SIGRIST, J.M.M.; De MARTIN, Z.J.; NISIDA, A.L.A.C.; BALDINI, V.L.S.; LEITE, R.S.S.F.; GARCIA, A.E.B. Mamão: cultura, matéria-prima, processamento e aspectos econômicos. 2 ed., rev. e ampl., Campinas: ITAL, 1989. p.1-178.

RUGGIERO, C. Propagação do mamoeiro. In: RUGGIERO, C. SIMPÓSIO BRASILEIRO SOBRE A CULTURA DO MAMOEIRO, 1., Jaboticabal-SP. Anais... Jaboticabal, p.79-87, 1980. 
SILVA, E.O. Efeito da embalagem plástica e da temperatura sobre a qualidade pós-colheita do mamão. Viçosa: UFV, 74p. 1995. Tese de Mestrado.

SOUZA, G. de. Características físicas, químicas e sensoriais do fruto de cinco variedades de mamoeiro (Carica papaya $L$.) cultivadas em Macaé-RJ. Campos dos Goytacazes, 1998. 94 p. Tese de Mestrado.

VIEGAS, P.R.A. Características químicas e físicas do mamão
(Carica papaya L.) cultivares 'Sunrise Solo' e 'Formosa' relacionados ao ponto de colheita. Viçosa: UFV, 1992. 82p. Tese de Mestrado.

VIEIRA, G.; VIEGAS, P.R.A.; NEVES, J.C.L.; AGNES, E.L.; OLIVEIRA, F.A.M.B. Influência da cultivar e do estádio de maturação em algumas características de frutos de mamão durante a pós-colheita. In: CONGRESSO BRASILEIRO DE FRUTICULTURA. 15., 1998. Poços de Caldas, Resumo... Poços de Caldas, 1998. p.508. 